\title{
Validated Chromatographic Methods for the Simultaneous Determination of Sodium Cromoglycate and Oxymetazoline Hydrochloride in a Combined Dosage Form
}

\author{
Maha A. Hegazy ${ }^{a}$, Medhat A. Al-Ghobashy ${ }^{a, b}$, Basma M. Eltanany ${ }^{a}$ and \\ Fatma I. Khattab a \\ ${ }^{a}$ Analytical Chemistry Department, Faculty of Pharmacy, Cairo University, Egypt \\ ${ }^{\mathrm{b}}$ Bioanalysis Research Group, Faculty of Pharmacy, Cairo University, Egypt
}

\begin{abstract}
:
Two chromatographic methods were developed and validated for the simultaneous determination of Sodium Cromoglycate (SCG) and Oxymetazoline Hydrochloride (OXMT). SCG and OXMT are administered in combination for effective treatment of nasal congestion and allergy. The first chromatographic method was based on usingaluminum TLC plates pre-coated with silica gel $\mathrm{GF}_{254}$ as the stationary phase and chloroform: methanol: toluene: triethylamine (5: 2: 4:1, by volume) as the mobile phase followed by densitometric measurement of the separated bands at $235 \mathrm{~nm}$. The second method is a high performance liquid chromatographic method for separation and determination of SCG and OXMT using reversed phase $\mathrm{C}_{18}$ column with isocratic elution. The mobile phase composed of acetonitrile: methanol $(2: 1, \mathrm{v} / \mathrm{v})$ at flow rate of $1.0 \mathrm{~mL} / \mathrm{min}$. Quantitation was achieved with UV detection at $220 \mathrm{~nm}$. The validity of the proposed methods was assessed using the standard addition technique. The obtained results were statistically compared with those obtained by the official methods, showing no significant difference with respect to accuracy and precision at $p=0.05$.
\end{abstract}

Keywords: Sodium cromoglycate; Oxymetazoline hydrochloride; TLC-densitometry; high performance liquid chromatography.

\section{Council for Innovative Research}

Peer Review Research Publishing System

\section{Journal: Journal of Advances in Chemistry}

Vol. 11, No. 8

editorjaconline@gmail.com, www.cirjac.com 


\section{Introduction}

Chemically, sodium cromoglycate (SCG) is 5,5'-(2-hydroxypropane-1,3-diyl)bis(oxy)bis(4-oxo-4H-chromene-2-carboxylic acid) disodium salt (Fig. 1a). It exerts its action via preventing the release of mediators that would normally attract inflammatory cells. [1] Oxymetazoline hydrochloride (OXMT) is chemically designated as 3-(4,5-dihydro-1 H-imidazol-2ylmethyl)-2,4-dimethyl-6-tert-setyl-phenol hydrochloride salt (Fig. 1b). It is a sympathomimetic agent that selectively acts on $\alpha_{1}$ and partially on $\alpha_{2}$ adrenergic receptors. [2] Both drugs are co-formulated in a nasal spray dosage form and are widely used for effective treatment of nasal congestion and allergy. Several methods have been reported for the determination of SCG in pharmaceutical preparations such as spectrophotometry [3, 4], electrophoresis [5], electrochemical $[6,7]$ and HPLC methods. [8-14] OXMT has also been analyzed by several methods in pharmaceutical preparations such as spectrophotometry [3, 15-23], capillary electrophoresis [24, 25], gas chromatography [26, 27] and HPLC. [28-35] Abdel-Aziz et al. [3] developed new accurate, sensitive and selective spectrophotometric and spectrofluorimetric methods for determination of SCG and OXMT. To the best of our knowledge, no reported chromatographic methods were found for simultaneous determination of the cited drugs in their combination. The aim of this work is to develop simple chromatographic methods for the simultaneous determination of SCG and OXMT in pharmaceutical dosage form.

\section{Experimental}

\subsection{Instruments}

The thin-layer chromatographic (TLC) system consisted of a Camag Linomat autosampler (Muttenzl, Switzerland), a Camag microsyringe $(100 \mathrm{~mL})$ and a Camag 35/N/30319 TLC scanner with win CATS software; an ultraviolet (UV) lamp with a short wavelength at $254 \mathrm{~nm}$ (Desaga, Wiesloch, Germany); and TLC plates precoated with silica gel G. $\mathrm{F}_{254} 10 \times 20$ $\mathrm{cm}, 0.25 \mathrm{~mm}$ thickness (Merck, Darmstadt, Germany).

HPLC system consisted of Agilent 1100 series liquid chromatograph, Waldbornn, Germany. It consists of Isocratic pumpmodel G 1310 A, UV detector-Model G 1314 A, A Rheodyne injector-Model 7225/77251, (Rohnert park, CA, USA) Equipped with a prominence Autosampler (modelSIL-20A). C18, Zorbax Eclipse XDB (4.6 × $150 \mathrm{~mm})$, particle size $(5 \mu \mathrm{m})$, USA.

\subsection{Materials and reagents}

\subsubsection{Pure standard}

SCG pure sample was supplied by SIGMA Pharmaceutical industries, Egypt. Pure sample of OXMT was supplied by National Organization for Drug Control and Research (NODCAR), Egypt. Their purity were checked and found to be 101.5 \pm 1.01 and $99.93 \pm 1.01$ for SCG and OXMT, respectively, according to the USP reference methods [36] which are spectrophotometric and HPLC methods for SCG and OXMT, respectively.

\subsubsection{Pharmaceutical dosage form}

Nasocrom ® nasal spray (SIGMA Pharmaceutical industries, Egypt), labeled to contain $2 \mathrm{~g}$ of SCG and $0.025 \mathrm{~g}$ of OXMT per $100 \mathrm{~mL}$ (Batch number: 11087) was obtained from the local market.

\subsubsection{Chemicals and reagents}

All chemicals used throughout the work were of analytical grade and solvents for HPLC were of HPLC grade. These included methanol, chloroform, triethylamine and acetonitrile (Sigma-Aldrich, Belgium), and double distilled deionized water (Otsuka, Cairo, Egypt). Toluene was purchased from Al-Nasr Pharmaceutical Chemicals Co., Cairo, Egypt.

\subsubsection{Standard solutions}

Standard stock solution of each of SCG and OXMT: $1.0 \mathrm{mg} / \mathrm{mL}$ in methanol (for TLC method) and $10 \mathrm{mg} / \mathrm{mL}$ of SCG and $1.0 \mathrm{mg} / \mathrm{mL}$ OXMT in mobile phase(for HPLC method).

\subsubsection{Working Solutions}

For HPLC method. Working solutions of SCG $(1.0 \mu \mathrm{g} / \mathrm{mL})$ and OXMT $(100 \mu \mathrm{g} / \mathrm{mL})$ were prepared from their respective stock solutions using mobile phase as a solvent.

\subsection{Procedures}

\subsubsection{Construction of the calibration curves}

For TLC-spectrodensitometric method.

Accuratly measured aliquots of SCG and OXMT stock standard solution $(1 \mathrm{mg} / \mathrm{mL})$ were spotted onto two different TLC plates using Camag Linomat autosampler with microsyringe $(100 \mu \mathrm{L})$. The plates were then developed by the ascending technique using chloroform: methanol: toluene: triethylamine (5: 2: 4:1, by volume) as a mobile phase. The plates were then removed and air-dried. The chromatogram was scanned at $235 \mathrm{~nm}$. Calibration curves representing the relationship 
between integrated peak area and the corresponding concentrations of each of SCG (0.4-4.4 $\mu \mathrm{g} / \mathrm{band})$ and OXMT (0.5$20.0 \mu \mathrm{g} / \mathrm{band}$ ) were plotted.

\subsubsection{For HPLC method:}

Aliquots of SCG and OXMT equivalent to $900-8000 \mu \mathrm{g}$ and $100-900 \mu \mathrm{g}$, respectively, where separately and accurately transferred each from its respective working standard solution $(1.0 \mathrm{mg} / \mathrm{mL}$ SCG and $0.1 \mathrm{mg} / \mathrm{mL}$ OXMT) into three separate sets of $10-\mathrm{mL}$ measuring flasks and the volume was then completed to the mark with the mobile phase (acetonitrile: methanol $(2: 1, \mathrm{v} / \mathrm{v}))$. A $20-\mu \mathrm{L}$ aliquot of each solution was injected into an C18, Zorbax Eclipse XDB $(4.6 \times 150 \mathrm{~mm})$, particle size $(5 \mu \mathrm{m})$, using the mobile phase, at flow rate $1.0 \mathrm{~mL} / \mathrm{min}$ and UV detection at $220 \mathrm{~nm}$. Two calibration curves were constructed by plotting the relative peak area, using an external standard of $400 \mu \mathrm{g} / \mathrm{mL}$ SCG and $50 \mu \mathrm{g} / \mathrm{mL}$ OXMT, against the corresponding concentrations of each drug.

\subsubsection{Application to pharmaceutical formulations}

Appropriate dilutions from Nasocrom ${ }^{\circledR}$ nasal drops were made using methanol to obtain solutions having concentrations within the linearity range of each of SCG and OXMT, these dilutions were analyzed by the proposed chromatographic methods as detailed under linearity. The concentrations of SCG and OXMT were obtained from the computed regression equations and the validity of the methods was further assessed by applying the standard addition technique

\section{Results}

Several trials were conducted to develop the optimum chromatographic conditions for the sufficient separation of both drugs. The results of the TLC system were satisfactory when using chloroform: methanol: toluene: triethylamine (5: $2: 4: 1$, by volume)as the mobile phase. Rf values were found to be $0.1 \pm 0.01$ and $0.3 \pm 0.01$ for SCG and OXMT, respectively as shown in (Fig. 2). This separation allows the determination of SCG and OXMT at $235 \mathrm{~nm}$ without any interference from each other.

HPLC method was also tried to separate SCG and OXMT, therefore several trials have been undertaken to reach the optimum stationary/mobile phases matching. Good chromatographic separation of the two drugs in their binary mixtures could be achieved by using an C18, Zorbax Eclipse XDB $(4.6 \times 150 \mathrm{~mm})$, particle size $(5 \mu \mathrm{m})$, with a mobile phase consisting of (acetonitrile: methanol $(2: 1, \mathrm{v} / \mathrm{v})$ ) at flow rate $1.0 \mathrm{~mL} / \mathrm{min}$, followed by UV detection at $220 \mathrm{~nm},(\mathrm{Fig} .3)$.

Calibration was performed for both TLC and HPLC for the determination of the cited drugs. An overall system suitability testing was calculated (Table I) to determine whether the operating system performed properly. The proposed methods were validated according to International Conference on Harmonization (ICH) guidelines (Table II). The table also shows the assay parameters of the regression equations and the ranges of concentration.

The proposed methods were successfully applied for determination of SCG and OXMT in Nasocrom ${ }^{\circledR}$ nasal spray. The results shown in table (III) were satisfactory. The validity of the proposed methods was assessed by applying the standard addition technique, no interference due to excipients was observed as shown from the results in table (III).

The results obtained by applying the proposed methods for analysis of pure SCG and OXMT compared to those obtained by applying the official methods [36], they showed no significance difference regarding accuracy and precision table (IV).

\section{Discussion}

Planar chromatography with precise application of the samples and computer controlled evaluation and quantification of the developed chromatograms has been considered to be a reliable technique for purity control and for quantitative drug testing [37]. Therefore the aim of this work is to develop simple, accurate, rapid, specific and valid spectro-densitometric method. This separation allows the determination of SCG and OXMT without any interference from each other. Linear relationship was found to exist between the integrated peak area of the separated bands at the selected wavelength (235 $\mathrm{nm}$ ) and the corresponding concentration of SCG in the range of $0.4-4.4 \mu \mathrm{g} / \mathrm{band}$ and a polynomial one was found in the range of $0.5-20.0 \mu \mathrm{g} / \mathrm{band}$ for OXMT, figures $(19,20)$.

The regression equations were computed and found to be:
$A=0.375 X+0.309$
$r=0.9999$
for SCG
$A=-0.003 X 2+0.219 X+0.282$
$r=0.9990$ for OXMT

Where $A$, is the integrated peak area $\times 10-4, X$ is the concentration in $\mu \mathrm{g} / \mathrm{band}$ and $r$ is the correlation coefficient.

The suggested chromatographic system for the HPLC method allows complete base line separation at reasonable time. The linearity of the detector's response of the studied drugs was determined by plotting relative peak area (calculated following the external standard technique using $400 \mu \mathrm{g} / \mathrm{mL}$ SCG and $50 \mu \mathrm{g} / \mathrm{mL}$ OXMT as the external standards for SCG and OXMT, respectively) versus concentrations and linear correlation was obtained. The regression equations were computed for SCG and OXMT and found to be:
$A=0.002 X+0.059$
$r=1.0000$
for SCG
$A=0.020 X+0.010$
$r=0.9995$
for OXMT

Where, $A$ is the relative peak area, $X$ is the drug concentration in $\mu \mathrm{g} / \mathrm{mL}$ and $r$ is the correlation coefficient. 


\subsection{Method Validation}

The proposed methods were validated according to the ICH Q2 (R1)recommendations [38]. The method was validated for parameterssuch as system suitability, linearity, limit of detection (LOD), limit of quantitation (LOQ), accuracy, precision and selectivity.

\subsubsection{System suitability}

The system suitability test is an integral part of chromatographic method development and it is used to verify that the systemis adequate for the analysis to be performed; the parameters Q8 for SCG and OXMT were evaluated. The suitability of the chromatographics ystem was determined according to USP guidelines and with acceptance of the obtained parameter values. [36]

\subsubsection{Linearity and ranges}

Under the above mentioned experimental conditions, linear relationships were obtained by plotting the drug concentrations either against integrated peak areas or relative peak areas for each drug, for TLC and HPLC methods, respectively.

\subsubsection{Accuracy}

The accuracy of the proposed methods was validated by analyzing pure samples of each SCG and OXMT in triplicate. The concentrations of the active drugs were calculated from the corresponding regression equations.

\subsubsection{Precision}

It was evaluated by calculating intra and inter-day precision. By repeating the assay of three different concentrations of each of the cited drugs three times in the same day and assaying the same samples in triplicate on three successive days using the developed chromatographic methods. RSD values were then calculated for each sample.

\subsubsection{Specificity}

The specificity of the developed methods was investigated by application of mixtures containing the two drugs in different ratios to TLC plate and the method under the chromatographic conditions were then followed. The bands of the two drugs in the prepared mixtures were confirmed by comparing their Rf values with that of standard drugs solutions. (in TLC method). Specificity was ascertained by analyzing different mixtures containing SCG and OXMT in different ratios. Parameters such as resolution, capacity and selectivity factors for the separated chromatographic peaks were then calculated (in HPLC method).

\section{Conclusion}

The suggested chromatographic methods provide simple, sensitive, accurate and reproducible methods for quantitative analysis of SCG and OXMT in their binary mixtures and pharmaceutical dosage form. The developed TLC method is highly sensitive. It has the advantages of short run time, large sample capacity and use of minimal volume of solvents. HPLC method gives a good resolution between the proposed components within suitable analysis time; it is highly specific but more expensive.

\section{References}

1. Drugs for the Treatment of Respiratory Diseases 2003.

2. Widdicombe, J., Microvascular anatomy of the nose, Allergy 52 (40 Suppl). Allergy, 1997. 52(40): p. 7-11.

3. Abdel-Aziz, O., et al., Novel spectroscopic methods for determination of Cromolyn sodium and Oxymetazoline hydrochloride in binary mixture. Spectrochimica Acta Part A: Molecular and Biomolecular Spectroscopy, 2014. 131: p. 59-66.

4. Ochoa de Aspuru, E. and A. ML Zatón, Binding of disodium cromoglycate to human serum albumin. Spectrochimica Acta Part A: Molecular and Biomolecular Spectroscopy, 1998. 54(7): p. 983-988.

5. Helle, A., et al., Quantitative determination of drug encapsulation in poly (lactic acid) nanoparticles by capillary electrophoresis. Journal of Chromatography A, 2008. 1178(1): p. 248-255.

6. Pereira, F., A. Fogg, and M. Zanoni, Regeneration of poly-L-lysine modified carbon electrodes in the accumulation and cathodic stripping voltammetric determination of the cromoglycate anion. Talanta, 2003. 60(5): p. 1023-1032.

7. Moreira, J.C., et al., Differential-pulse adsorptive stripping voltammetric determination of sodium cromoglycate at a hanging mercury drop electrode. Analyst, 1992. 117(6): p. 989-991.

8. Liu, X.y., et al., Determination of sodium cromoglycate in human plasma by liquid chromatography with tandem mass. Biomedical Chromatography, 2008. 22(9): p. 1021-1027.

9. Barnes, M., R. Mansfield, and S. Thatcher, The selection of an ion pairing reagent for developing and validating a stability-indicating HPLC method for cromolyn sodium and its known impurities. Journal of liquid chromatography \& related technologies, 2002. 25(12): p. 1721-1745. 
10. Ozoux, M., et al., Determination of sodium cromoglycate in human plasma by liquid chromatography-mass spectrometry in the turbo ion spray mode. Journal of Chromatography B: Biomedical Sciences and Applications, 2001. 765(2): p. 179-185.

11. Segall, A., et al., High performance liquid chromatographic determination of sodium cromoglycate. Drug development and industrial pharmacy, 1997. 23(8): p. 839-842.

12. Mawatari, K.i., et al., Determination of Disodium Cromoglycate in Human Urine by High-performance Liquid Chromatography With Post-column Photoirradiation-Fluorescence Detection. Analyst, 1997. 122(7): p. 715-717.

13. Ng, L.L., Reversed-phase liquid chromatographic determination of cromolyn sodium in drug substance and select dosage forms. Journal of AOAC International, 1993. 77(6): p. 1689-1694.

14. Gardner, J.J., Determination of sodium cromoglycate in human urine by high-performance liquid chromatography on an anion-exchange column. Journal of Chromatography B: Biomedical Sciences and Applications, 1984. 305(1): p. 228-232.

15. Wang, N.N., et al., Flow-injection chemiluminescence method for the determination of naphazoline hydrochloride and oxymetazoline hydrochloride. Luminescence, 2009. 24(3): p. 178-182.

16. Lahuerta Zamora, L., et al., Prediction of the chemiluminescent behavior of pharmaceuticals and pesticides. Analytical chemistry, 2001. 73(17): p. 4301-4306.

17. Sankar, D.G., et al., Indian Drugs, 1989. 26(7): p. 348-351.

18. Sankar, D.G., et al., Indian J. Pharm. Sci., 1987. 49(2): p. 69-71.

19. Anjaneyulu, Y., et al., Extractive Spectrophotometric Determination of Some Imidazoline Drugs as lon Pair with Rose Bengal. Indian Drugs, 1985. 22(12): p. 655.

20. Dixit, R.K., S.K. Misra, and B.B. Awasthi, Indian Drugs, 1984. 22(1): p. 31-33.

21. Shingbal, D.M. and S.D. Naik, East. Pharm., 1983. 26(308): p. 201.

22. Kamalapurkar, O.S. and S.R.S. Priolkar, Indian Drugs, 1983. 20(4): p. 164-166.

23. Shingbal, D. and K. Sawant, Colorimetric Determination of Oxymetazoline Hydrochloride. Indian Drugs, 1982. 20(3): p. 106.

24. Chen, Q., et al., Nonaqueous capillary electrophoresis conditions for the simultaneous separation of eight alphaadrenergic blocking agents. Analytical and bioanalytical chemistry, 2010. 398(2): p. 937-942.

25. Gil Agusti, M., et al., Determination of active ingredients in cough-cold preparations by micellar liquid chromatography. Talanta, 2001. 54(4): p. 621-630.

26. Fragkaki, A., M. Koupparis, and C. Georgakopoulos, Quantitative structure-retention relationship study of $\alpha$-, $\beta<$ sub $>$ $1</$ sub $>$-, and $\beta<$ sub $>2</$ sub $>$-agonists using multiple linear regression and partial least-squares procedures. Analytica chimica acta, 2004. 512(1): p. 165-171.

27. Massaccesi, M., [Gas chromatographic determination of some imidazolines in pharmaceutical preparations using the FFAP in stationary phase]. Pharmaceutica Acta Helvetiae, 1986. 62(10-11): p. 302-305.

28. Khan, G.A., et al., The development and application of a system for simultaneously determining anti-infectives and nasal decongestants using on-line solid-phase extraction and liquid chromatography-tandem mass spectrometry. Journal of pharmaceutical and biomedical analysis, 2012. 66(1): p. 24-32.

29. Vucicevic, K., et al., An experimental design approach to selecting the optimum HPLC conditions for the determination of 2-arylimidazoline derivatives. Journal of Liquid Chromatography \& Related Technologies, 2009. 32(5): p. 656-667.

30. Golubitskii, G., E. Basova, and V. Ivanov, Application of gradient high-performance liquid chromatography to the analysis of some multicomponent pharmaceutical preparations. Journal of Analytical Chemistry, 2008. 63(9): p. 875880.

31. Sudsakorn, S., L. Kaplan, and D.A. Williams, Simultaneous determination of triamcinolone acetonide and oxymetazoline hydrochloride in nasal spray formulations by HPLC. Journal of pharmaceutical and biomedical analysis, 2006. 40(5): p. 1273-1280.

32. Detroyer, A., et al., Exploratory chemometric analysis of the classification of pharmaceutical substances based on chromatographic data. Journal of Chromatography A, 2000. 897(1): p. 23-36.

33. Hayes, F.J., et al., Rapid liquid chromatographic-mass spectrometric assay for oxymetazoline in whole rat blood. Journal of Chromatography A, 1995. 692(1): p. 73-81.

34. De Orsi, D., et al., Simultaneous determination of ephedrine and 2-imidazolines in pharmaceutical formulations by reversed-phase HPLC. Journal of Liquid Chromatography \& Related Technologies, 1995. 18(16): p. 3233-3242. 
35. Hoffmann, T., R. Thompson, and J. Seifert, Determination of the nasal decongestant, oxymetazoline hydrochloride, in pharmaceutical formulations by HPLC. Drug development and industrial pharmacy, 1989. 15(5): p. 743-757.

36. "The National Formulary USP"United States Pharmacopeia convention Inc, 2011.

37. Renger, B. In Proceedings of the sixth international symposium on Instrumental planner chromatography. in Institute for chromatography. 1991. Bad Duerkheim.

38. ICH, Q2 (R1) Validation of Analytical Procedures, in: Proceeding of the International Conference on Harmonization. 2005. Geneva.

Table I: Parameters required for system suitability test of TLC-densitometric and HPLC methods.

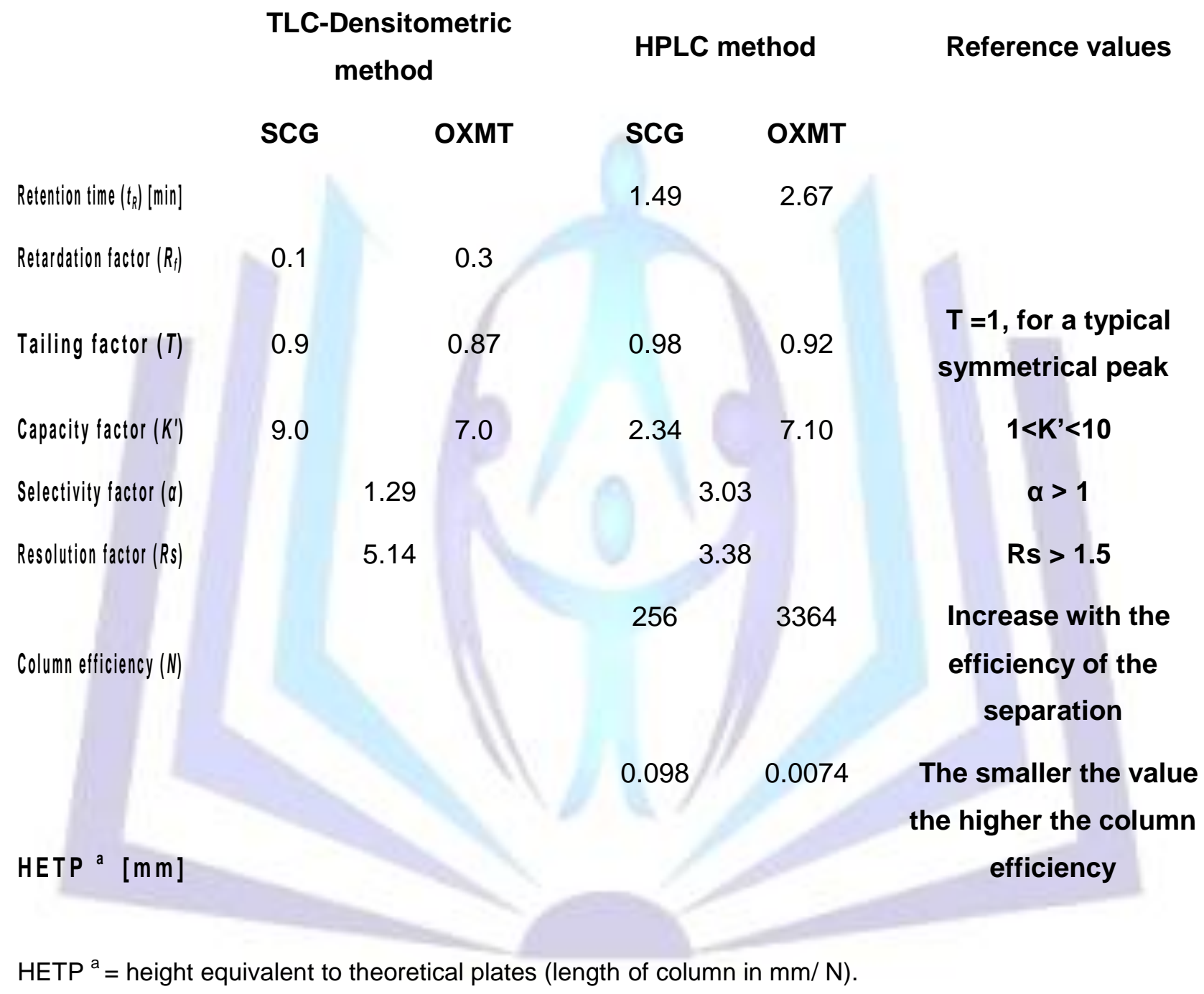


Table II: Assay validation sheet of the proposed methods for the simultaneous determination of Sodium cromoglycate (SCG) and Oxymetazoline hydrochloride (OXMT).

\section{Parameters}

\section{Range}

Slope 1

Slope 2

Intercept

SE of the slope

SE of the intercept

Correlation coefficient ( $r$ )

LOD

LOQ

Accuracy

(Mean \pm RSD)

Precision (RSD)

Repeatability

Intermediate precision

\section{TLC-Densitometric method}

SCG

$0.4-4.4 \mu \mathrm{g} / \mathrm{band}$

0.375

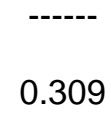

0.0084

0.0232

0.9999

$0.100(\mu \mathrm{g} / \mathrm{band})$

$0.400(\mu \mathrm{g} / \mathrm{band})$

$100.67 \pm 1.805$

0.998

1.709
OXMT

$0.5-20.0 \mu \mathrm{g} / \mathrm{band}$

$-0.003$

0.219

0.282

0.0045

0.0525

0.9990

$0.150(\mu \mathrm{g} / \mathrm{band})$

$0.500(\mu \mathrm{g} / \mathrm{band})$

$99.63 \pm 1.290$
HPLC method

SCG

OXMT

$90-800 \mu \mathrm{g} / \mathrm{mL} \quad 10-90 \mu \mathrm{g} / \mathrm{mL}$

0.002

0.020

0.059

0.010

0.0003

0.0002

0.0136

0.0127

1.0000

0.9995

$29.16 \mu \mathrm{g} / \mathrm{mL}$

$2.71 \mu \mathrm{g} / \mathrm{mL}$

$87.48 \mu \mathrm{g} / \mathrm{mL}$

$8.12 \mu \mathrm{g} / \mathrm{mL}$

$100.71 \pm 1.652$

$99.65 \pm 1.154$

${ }^{a}$ The intraday RSD \% and ${ }^{\mathrm{b}}$ The inter-day RSD \%, for TLC RSD\% of three concentrations (1.50, 2.50 and 3.50 $\mu \mathrm{g} / \mathrm{band})$ of SCG and $(3.50,5.50$ and $7.50 \mu \mathrm{g} / \mathrm{band})$ of OXMT repeated three times within the day. For HPLC RSD\% of three concentrations $(90.00,150.00$ and $500.00 \mu \mathrm{g} / \mathrm{mL})$ of SCG and $(10.00,50.00$ and $80.00 \mu \mathrm{g} / \mathrm{mL})$ of OXMT repeated three times within the day. 
Table III: Determination of Sodium cromoglycate (SCG) and Oxymetazoline hydrochloride (OXMT) in their Dosage form and application of standard addition technique using the proposed methods.

\begin{tabular}{|c|c|c|c|c|c|c|c|}
\hline \multirow{2}{*}{$\begin{array}{c}\text { Nasocrom }{ }^{\circledR} \text { nasal drops } \\
\text { B. N. } \mathbf{8 0 7 2 4}\end{array}$} & \multicolumn{2}{|l|}{ 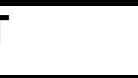 } & C & \multicolumn{2}{|r|}{$\mathrm{H}$} & \multicolumn{2}{|c|}{$\begin{array}{lll}P & L & C\end{array}$} \\
\hline & $S$ & C $\quad \mathbf{G}$ & $\begin{array}{llll}O & X & M & T\end{array}$ & $\mathbf{S}$ & C & G & $\begin{array}{llll}O & X & M & T\end{array}$ \\
\hline Mean Recovery ${ }^{a}$ & 104. & $00 \pm 1.351$ & $100.83 \pm 2.100$ & & $56 \pm 0$ & & $101.16 \pm 0.960$ \\
\hline Standard addition (meantRSD) & 99.4 & $45 \pm 1.141$ & $100.73 \pm 1.548$ & & $0 \pm 0$ & & $100.63 \pm 1.475$ \\
\hline
\end{tabular}

${ }^{a}$ Average of three determinations of dosage form.

${ }^{b}$ Average of three determinations of dosage form after the addition of different amounts of SCG or OXMT pure standard (standard addition technique).

Table IV: Statistical comparison for the results obtained by the proposed methods and the official methods for the analysis of Sodium cromoglycate (SCG) and Oxymetazoline hydrochloride (OXMT).

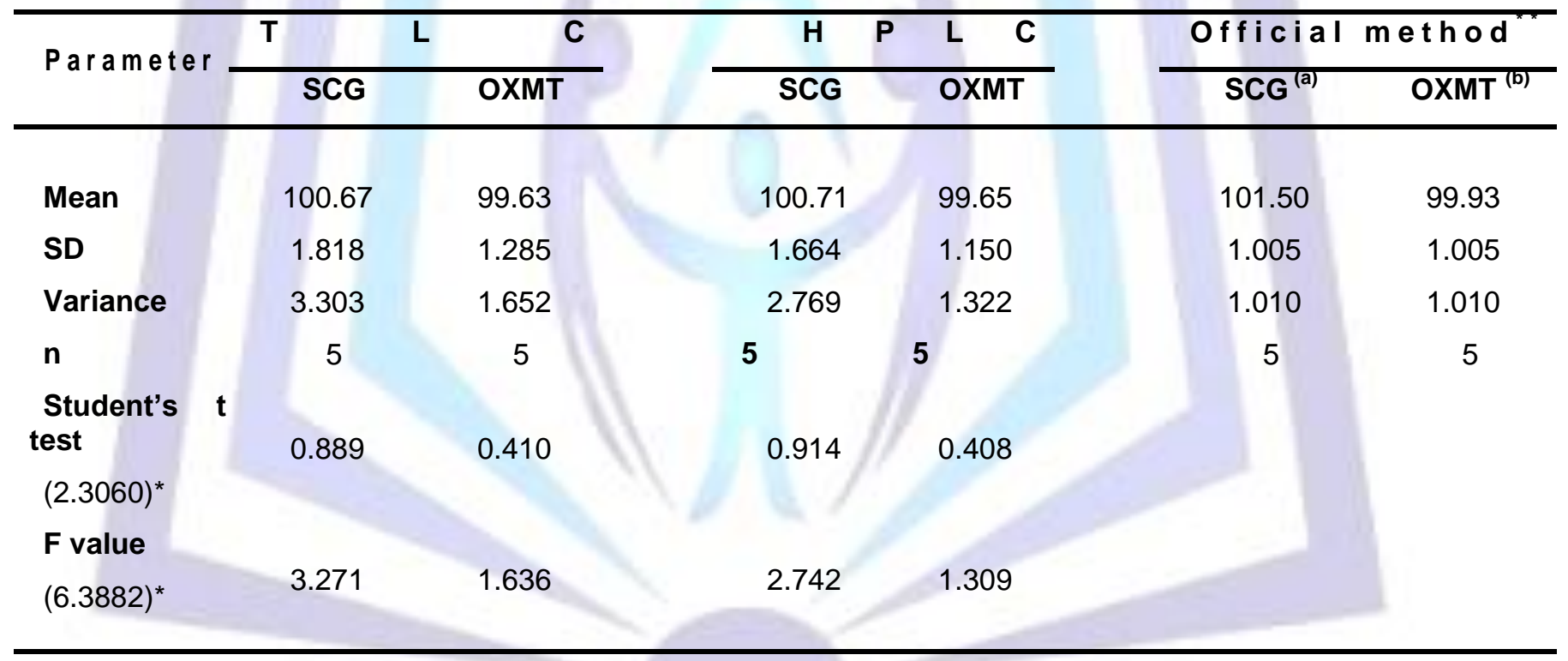

* These values represent the corresponding tabulated values of $t$ and $F$ at $P=0.05$

** "The National Formulary USP" United States Pharmacopeia convention Inc. 2011.

a) Direct absorbance measurement at $\lambda \max 326 \mathrm{~nm}$ using Sodium phosphate buffer ( $\mathrm{pH} 7.4$ ) as a blank.

b) HPLC method; mobile phase [water: methanol: $1 \mathrm{M}$ sodium acetate: glacial acetic acid (46:40: 10:4)] with UV detection at $280 \mathrm{~nm}$ 
<smiles>O=C([O-])c1cc(=O)c2c(OCC(O)COc3cccc4oc(C(=O)[O-])cc(=O)c34)cccc2o1</smiles>

(a)<smiles>Cc1cc(C(C)(C)C)c(O)c(C)c1CC1=NC[C@H](Cl)N1</smiles>

(b)

Figure 1: Chemical structures of (a) sodium cromoglycate and (b) oxymetazoline hydrochloride

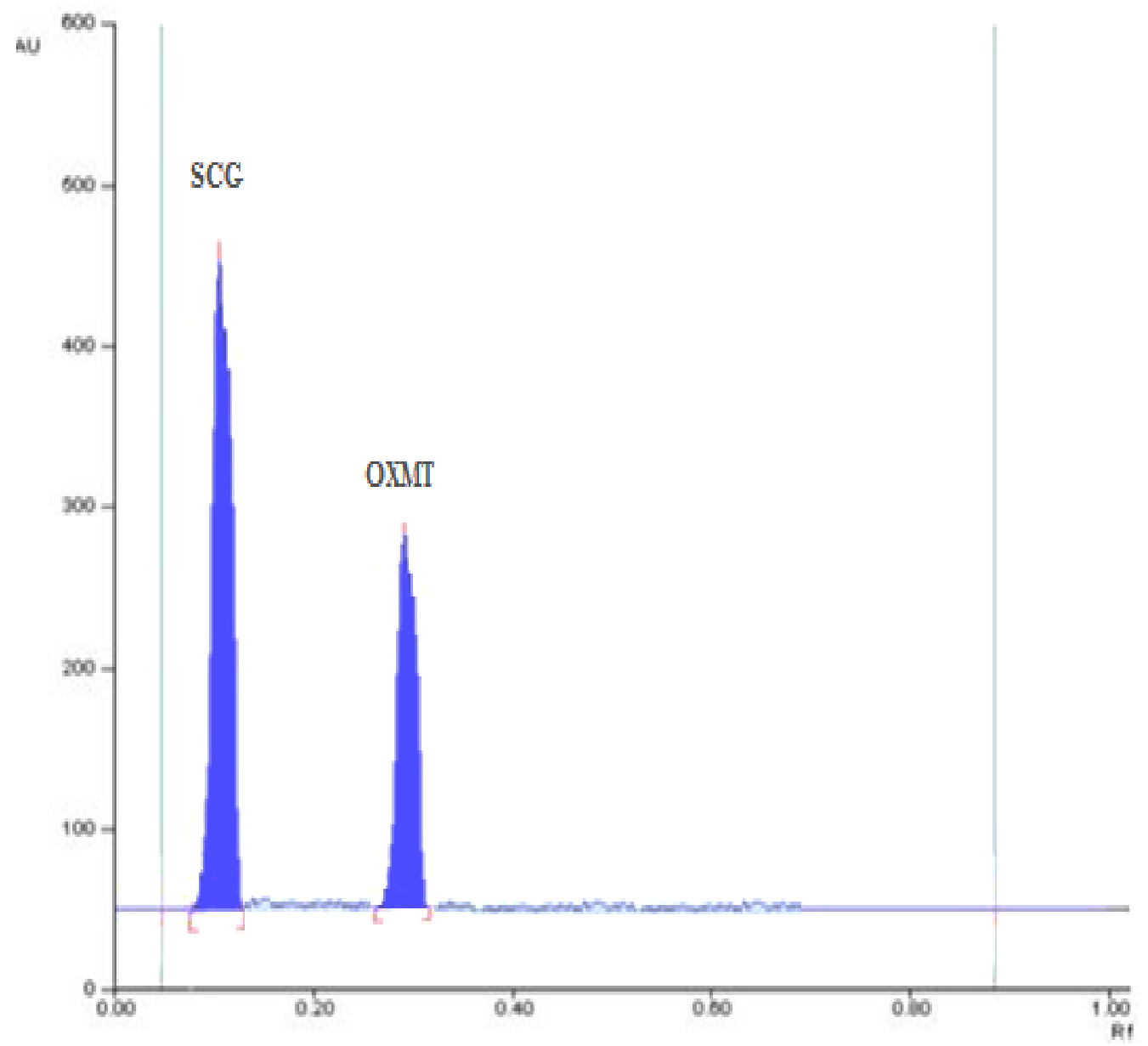

Fig. 2: TLC chromatogram of mixture of Sodium Cromoglycate (SCG) (RF=0.10 \pm .0 .01 ) and Oxymetazoline Hydrochloride (OXMT) $(R F=0.30 \pm 0.01)$ at $235 \mathrm{~nm}$ using chloroform: methanol: toluene: triethylamine (5: 2: 4:1, by volume) as a developing system. 
WWD1 A, Wavelength $=220 \mathrm{~nm}$.

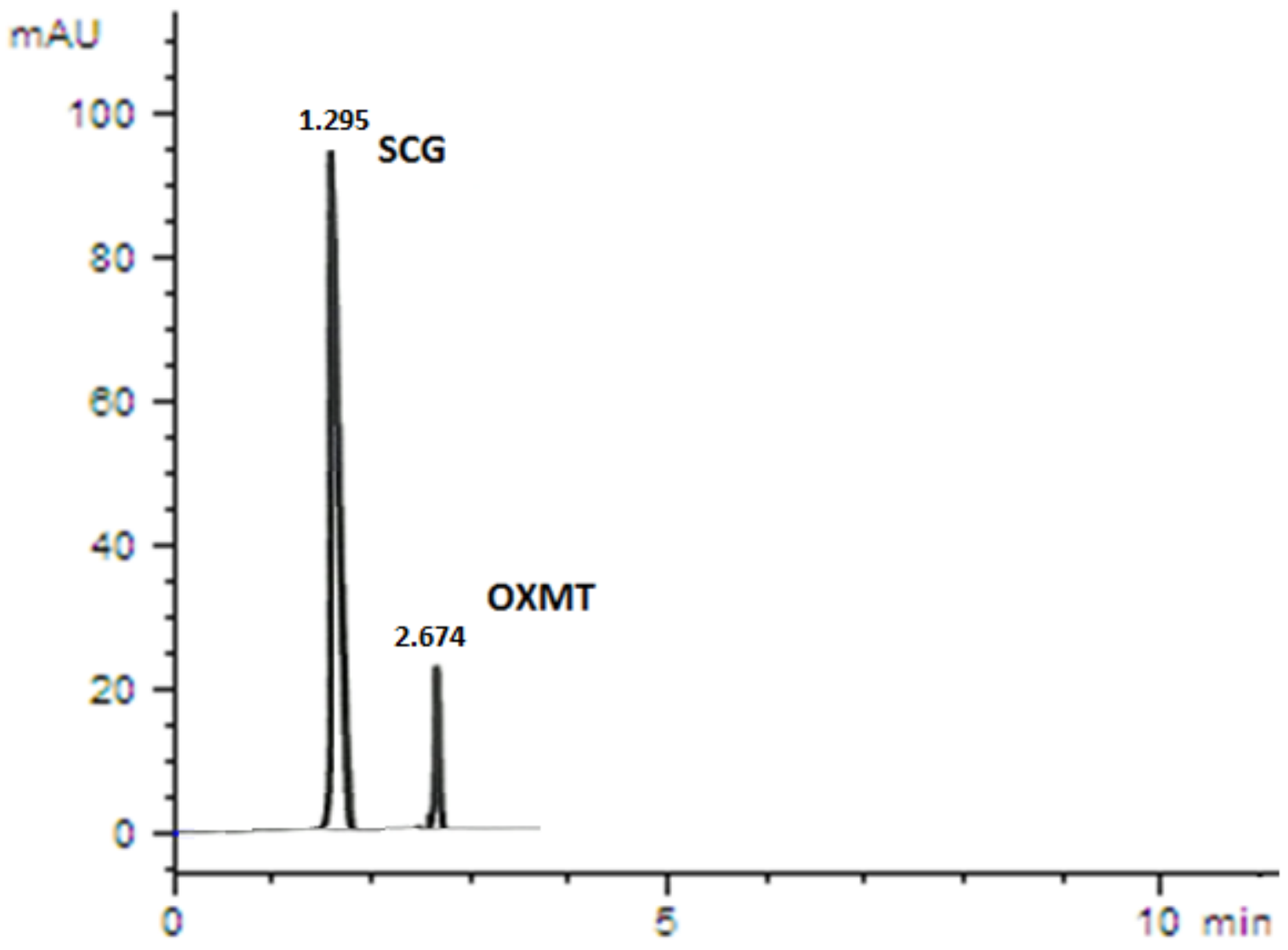

Fig. 3: HPLC chromatogram of a resolved mixture of Sodium Cromoglycate (SCG) (tR=1.49) and Oxymetazoline Hydrochloride (OXMT) (tR=2.67) using mobile phase of acetonitrile: methanol (2: 1, $\mathbf{v} / \mathbf{v})$. 